Article

\title{
Filtration Efficiency of Electret Air Filters Reinforced by Titanium Dioxide
}

\author{
Ching-Wen Lou 1,2,3,4,5, Ying-Huei Shih ${ }^{6}$, Chen-Hung Huang ${ }^{7,}{ }^{*}$, Shu-An Lee ${ }^{8}$, \\ Yueh-Sheng Chen ${ }^{9}$ and Jia-Horng Lin $1,2,6,10,11,12, *$ iD
}

1 Fujian Key Laboratory of Novel Functional Fibers and Materials, Minjiang University, Fuzhou 350108, China; cwlou@asia.edu.tw

2 Advanced Medical Care and Protection Technology Research Center, College of Textile and Clothing, Qingdao University, Qingdao 266071, China

3 Department of Bioinformatics and Medical Engineering, Asia University, Taichung 41354, Taiwan

4 Innovation Platform of Intelligent and Energy-Saving Textiles, School of Textiles, Tianjin Polytechnic University, Tianjin 300387, China

5 Department of Medical Research, China Medical University Hospital, China Medical University, Taichung 40402, Taiwan

6 Department of Fiber and Composite Materials, Feng Chia University, Taichung 40724, Taiwan; syhlhpc1990715@hotmail.com

7 Department of Aerospace and Systems Engineering, Feng Chia University, Taichung 40724, Taiwan

8 Department of Environmental Engineering and Science, Feng Chia University, Taichung 40724, Taiwan; salee@fcu.edu.tw

9 Department of Biomedical Imaging and Radiological Science, China Medical University, Taichung 40402, Taiwan; yuehsc@mail.cmu.edu.tw

10 School of Chinese Medicine, China Medical University, Taichung 40402, Taiwan

11 Laboratory of Fiber Application and Manufacturing, Department of Fiber and Composite Materials, Feng Chia University, Taichung 40724, Taiwan

12 Department of Fashion Design, Asia University, Taichung 41354, Taiwan

* Correspondence: chhuang@fcu.edu.tw (C.-H.H.); jhlin@fcu.edu.tw (J.-H.L.); Tel.: +886-4-2451-7250 (ext. 3405) (J.-H.L.); Fax: +886-4-2451-0871 (J.-H.L.);

Received: 11 March 2020; Accepted: 9 April 2020; Published: 13 April 2020

\begin{abstract}
In this study, titanium dioxide $\left(\mathrm{TiO}_{2}\right)$, a mineral with a potential and supercapacitor, is used as the reinforcing material to improve the filtration efficacy of electret melt-blown fabrics. Next, the electret melt-blown fabrics are evaluated in terms of surface voltage and filtration efficiency, thereby examining the influences of the $\mathrm{TiO}_{2}$ ratio and electric field intensity. The test results indicate that the filtration efficiency is proportional to the ratio of $\mathrm{TiO}_{2}$ and electric field intensity. In particular, with a $\mathrm{TiO}_{2}$ ratio of $3 \mathrm{wt} \%$ and an electric field intensity of $2.5 \mathrm{kV} / \mathrm{cm}$, the electret melt-blown fabrics demonstrate a maximal filtration efficiency of $96.32 \%$, a lowest pressure drop of $40 \mathrm{~Pa}$, and an optimal quality factor of $0.083 \mathrm{~Pa}^{-1}$.
\end{abstract}

Keywords: titanium dioxide $\left(\mathrm{TiO}_{2}\right)$; filtration efficiency; surface voltage; surface potential; quality factor

\section{Introduction}

The development of industry and the progress of traffic have brought with them many negative influences, such as air, noise, and water pollution. In particular, air pollution causes damage to human health, causing many people to suffer from allergy or respiratory diseases [1], which promotes researchers' interest in the filtering of air pollutants. The issue of polluted air is commonly addressed using air filter materials that are divided into mechanical and nonmechanical types. As for 
nonmechanical types, polymer electret filter materials garner the most attention because of their high efficiency and low pressure drop [2-6].

Polymer electret filter materials are extensively used in the air filtration field, and the most effective polymer is poly(tetrafluoroethylene) (PTFE). However, PTFE has a high cost and challenging production issues, which makes polypropylene (PP) a staple material for air filtration products in the market. In addition, there are two approaches to strengthen the electret efficacy. One approach is to add dielectric-constant reinforcing materials to the filters, thereby storing much more space charges [7] and thus obtaining higher surface voltage. The reinforcing materials are lithium niobate [8], silicon dioxide [9], nanoscale graphite platelets [10], and barium titanate $[7,11,12]$. The other approach is to add a nucleating agent that increases the crystallinity of polymers and to obtain greater crystalline and amorphous regions to house more space charges. The nucleating agents are magnesium stearate [13], stearate [14], modified rosin [14], polycarbonate [15], tourmaline [16], DMDBS (3:2, 4-bis(3,4-dimethyldibenzylidene) sorbitol) sorbitol) [17], and NA11 (sodium 2,2'-methylene-bis(4,6-di-tertbutylphenyl)-phosphate) [17].

Titanium dioxide $\left(\mathrm{TiO}_{2}\right)$ is one of the materials commonly used in paints and cosmetics [18]. Because of its high dielectric constant, $\mathrm{TiO}_{2}$ is also used in semiconductors and solar cells. Tyagi et al. found that $\mathrm{TiO}_{2}$ had excellent charge storage capacity and a great potential as a supercapacitor [19]. Prateek et al. used $\mathrm{TiO}_{2}$ as the core to be synthesized with titanium compounds, producing materials that had a greater dielectric constant and specific energy when compared to poly(vinylidene fluoride) (PVDF) [20]. Due to the aforementioned upsides of $\mathrm{TiO}_{2}$, Viraneva et al. added $\mathrm{TiO}_{2}$ to polypropylene (PP) in the production of composite films. It was found that the surface potential was attenuated in a shorter time when the $\mathrm{TiO}_{2}$ ratio was increased, which might be attributed to the fact that a higher $\mathrm{TiO}_{2}$ ratio had a positive influence on the conductivity [21]. Similar findings were found in the study by $\mathrm{Zha}$ et al., where $\mathrm{TiO}_{2}$ was incorporated with polyimide to form nanocomposite membranes. They found that a $\mathrm{TiO}_{2}$ ratio exceeding $5 \mathrm{wt} \%$ resulted in a significant improvement in the conductivity [22]. Because one feature of photocatalysis is to purify air, $\mathrm{TiO}_{2}$ has been commonly investigated in previous studies on air filter materials [23-27]. For example, Lee et al. strengthened the decomposition of benzene and toluene by means of this particular feature of $\mathrm{TiO}_{2}$ [23]. Because the majority of studies focused on the photocatalysis purifying feature of $\mathrm{TiO}_{2}$ where air filtration was concerned and the electret materials were made in the form of membranes or composites, this study incorporates $\mathrm{TiO}_{2}$ with PP, thereby forming an air filter featuring a fiber morphology. Afterward, the fiber morphology, surface potential, and static electricity filtration efficiency of electret melt-blown fabrics were evaluated, examining the effects of the presence of $\mathrm{TiO}_{2}$.

\section{Materials and Methods}

\subsection{Materials}

PP powders (Metocene MF650Y, Polymirae Co., Ltd., Korea) were a homopolymer with a melt flow rate of $1800 \mathrm{~g} / 10 \mathrm{~min}\left(230,2.16 \mathrm{~kg}\right.$ ). The $\mathrm{TiO}_{2}$ (R-103, E Chang Trading Co., Ltd., Taiwan) had a purity of $98 \%$ and a particle diameter of $0.23 \mu \mathrm{m}$. Herein, the range of particle diameter was between 0.1 and $0.6 \mu \mathrm{m}$. NaCl (Shimakyu's Pure Chemicals Co., Ltd., Japan) had a purity of $99.8 \%$.

\subsection{Preparation of Filtration}

First, $\mathrm{PP}$ powders and $\mathrm{TiO}_{2}(1,2,3$, or $4 \mathrm{wt} \%)$ were made into $\mathrm{PP} / \mathrm{TiO}_{2}$ granules, then melt-blown fabrics using a melt-blown machine ((Tianjin Shengruiyuan Machinery Technology, China), and finally electret melt-blown fabrics using a corona charging device (Taiwan). Table 1 shows the properties of different electret melt-blown fabrics. In addition, Figure 1 also indicates that the $\mathrm{TiO}_{2}$ content is not correlated with fiber diameters. Because this study examines the influences of $\mathrm{TiO}_{2}$ on the electrostatic filtration efficiency of electret melt-blown fabrics, the parameters were adjusted to obtain comparable fiber diameters on purpose. 
Table 1. Intrinsic properties of samples made of different parameters.

\begin{tabular}{cccccc}
\hline $\begin{array}{c}\mathbf{T i O}_{2} \text { Ratio } \\
(\mathbf{w t} \mathbf{)})\end{array}$ & $\begin{array}{c}\text { Electric Field } \\
\text { Intensity } \\
(\mathbf{k V} / \mathbf{c m})\end{array}$ & $\begin{array}{c}\text { Basis Weight } \\
\left(\mathbf{g} / \mathbf{m}^{\mathbf{2}}\right)\end{array}$ & $\begin{array}{c}\text { Thickness } \\
(\mathbf{m m})\end{array}$ & $\begin{array}{c}\text { Fiber Diameter } \\
(\boldsymbol{\mu m})\end{array}$ & $\begin{array}{c}\text { Air } \\
\text { Permeability } \\
\left(\mathbf{c m}^{3} / \mathbf{s} / \mathbf{c m}^{2}\right)\end{array}$ \\
\hline & 1.5 & $68.3 \pm 4.8$ & $0.63 \pm 0.04$ & $5.73 \pm 2.97$ & $64.43 \pm 3.52$ \\
1 & 2 & $76.5 \pm 6.4$ & $0.65 \pm 0.09$ & $6.18 \pm 3.13$ & $60.81 \pm 4.59$ \\
& 2.5 & $69.4 \pm 3.4$ & $0.64 \pm 0.09$ & $5.91 \pm 3.67$ & $63.64 \pm 8.07$ \\
& 1.5 & $75.1 \pm 4.5$ & $0.65 \pm 0.05$ & $6.47 \pm 3.25$ & $61.67 \pm 4.09$ \\
2 & 2 & $73.3 \pm 6.8$ & $0.64 \pm 0.04$ & $6.33 \pm 1.98$ & $67.16 \pm 5.24$ \\
& 2.5 & $67.0 \pm 8.9$ & $0.62 \pm 0.04$ & $6.76 \pm 3.91$ & $66.87 \pm 5.12$ \\
3 & 1.5 & $63.5 \pm 11.3$ & $0.68 \pm 0.07$ & $6.02 \pm 3.28$ & $61.06 \pm 4.23$ \\
& 2 & $70.0 \pm 8.6$ & $0.61 \pm 0.06$ & $5.97 \pm 3.77$ & $64.50 \pm 4.84$ \\
& 2.5 & $66.5 \pm 8.2$ & $0.65 \pm 0.05$ & $6.73 \pm 4.12$ & $67.31 \pm 3.9$ \\
4 & 1.5 & $73.5 \pm 5.8$ & $0.64 \pm 0.02$ & $5.39 \pm 2.49$ & $62.00 \pm 4.17$ \\
& 2 & $71.6 \pm 4.4$ & $0.62 \pm 0.04$ & $6.74 \pm 3.74$ & $59.3 \pm 5.72$ \\
& 2.5 & $78.8 \pm 7.1$ & $0.68 \pm 0.06$ & $6.47 \pm 3.81$ & $68.65 \pm 8.36$ \\
\hline
\end{tabular}

${ }^{*}$ All of the samples are charged for $1 \mathrm{~min}$ at a distance of $10 \mathrm{~cm}$, an ambient temperature of $25^{\circ} \mathrm{C}$, and a humidity of $40 \%$. As an electric field intensity of $3 \mathrm{kV} / \mathrm{cm}$ generates arc, the maximum electric field intensity used in this study is $2.5 \mathrm{kV} / \mathrm{cm}$.

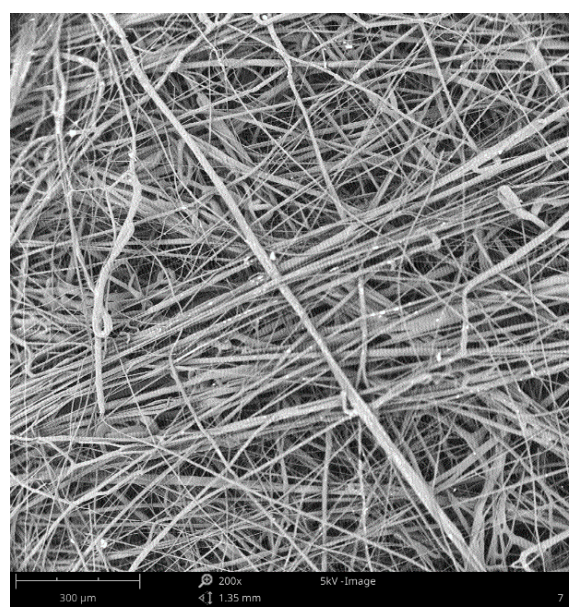

(a)

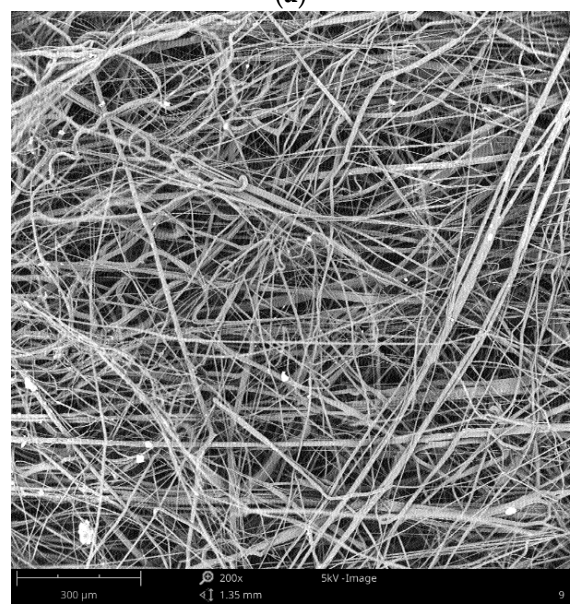

(c)

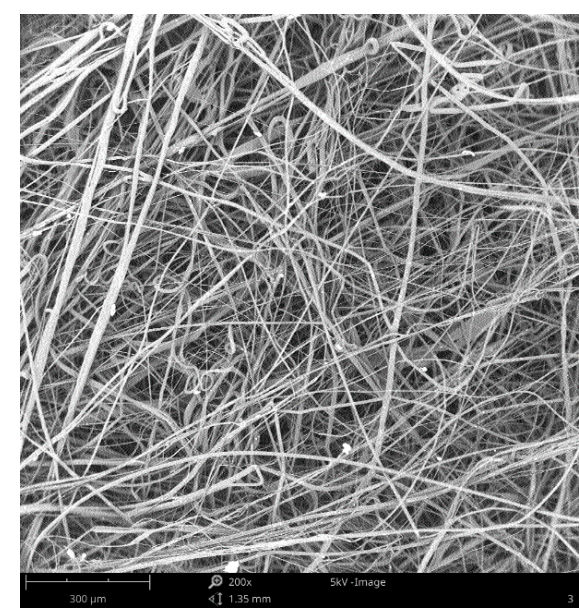

(b)

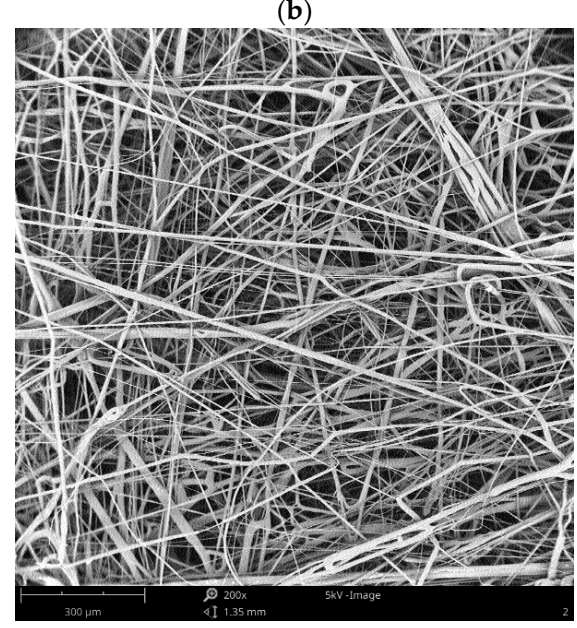

(d)

Figure 1. SEM images of electret melt-blown fabrics as related to the $\mathrm{TiO}_{2}$ content of (a) 1, (b) 2, (c) 3, and (d) $4 \mathrm{wt} \%$. 


\subsection{Testing}

\subsubsection{Surface Voltages}

A static meter (Model 5740, TAKK Industries Inc., US) is used to measure the surface voltage with a distance being $10 \mathrm{~cm}$. The test results are recorded.

\subsubsection{Surface Resistivity}

A resistivity meter (OHM-STAT RT-1000, Static Solutions Inc., US) with a test voltage of $100 \mathrm{~V}$ was used for the surface resistivity measurement. The two test probes weighing $5 \mathrm{lb}$ had a diameter of $2.5 \mathrm{in}$.

\subsubsection{Filtration Efficiency and Pressure Drop}

An electrical low pressure impactor (ELPI ${ }^{\mathrm{TM}}$, Dekati, Finland) was used for the measurement, with a gas flow of $85 \pm 4 \mathrm{~L} / \mathrm{min}$ and the particulate concentration of $200 \mathrm{mg} / \mathrm{m}^{3}(\mathrm{NaCl})$. Next, the particulate concentrations before and after the filtration process were obtained to compute the filtration efficiency. Moreover, a micromanometer (Models PVM 610, Airflow Measurements Ltd., UK) was used to measure the difference in the pressure at both ends of the filtering materials, using the following equation:

$$
\mathrm{FE}=\frac{\mathrm{C}_{0}-\mathrm{C}_{\mathrm{i}}}{\mathrm{C}_{0}} \times 100 \%
$$

where FE means the filtration efficiency, and $C_{0}$ and $C_{i}$ mean the particulate concentration before and after the filtration process, respectively. Figure 2 illustrates the filtration efficiency and pressure drop tests.

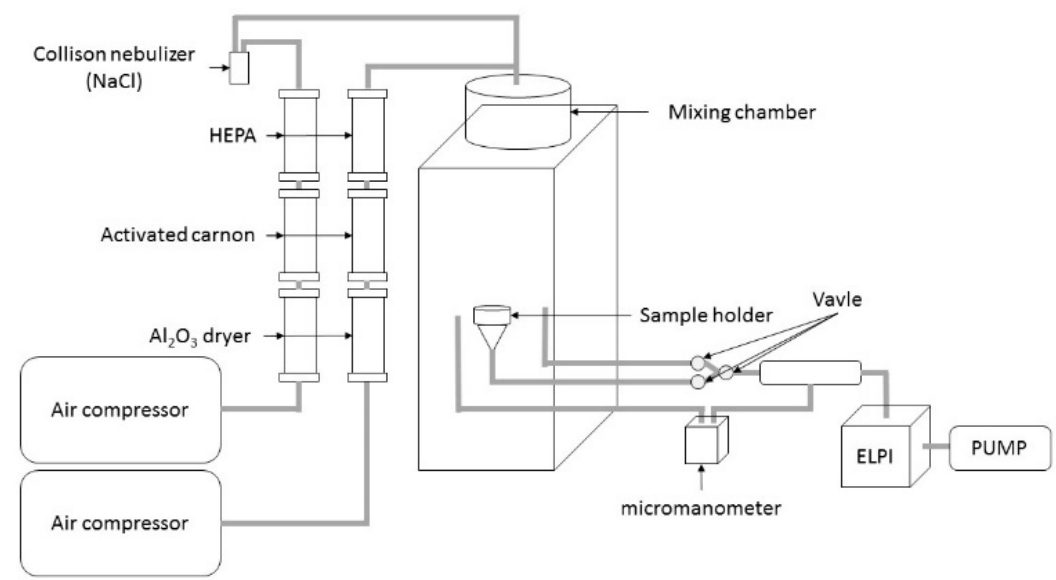

Figure 2. Diagram of the filtration efficiency (FE) and pressure drop tests.

\subsubsection{Differential Scanning Calorimeters}

A differential scanning calorimeter (DSC, Q200, TA Instruments., USA) was used to measure the apparent enthalpy of crystallization. The heating and cooling rates were $10^{\circ} \mathrm{C} / \mathrm{min}$. The crystallinity is computed using the equation as follows:

$$
\mathrm{Xc}_{\mathrm{c}}(\%)=\frac{\Delta H_{m}}{\Delta H_{m}^{0}} \times 100 \%
$$

where $\mathrm{X}_{\mathrm{c}}$ is the crystallinity, $\Delta \mathrm{H}_{\mathrm{m}}$ is the apparent enthalpy of crystallization, and $\Delta \mathrm{H}^{0}{ }_{\mathrm{m}}$ is the enthalpy of crystallization when PP has $100 \%$ crystallinity. 


\section{Results and Discussion}

\subsection{Surface Voltage}

The purpose of adding $\mathrm{TiO}_{2}$ is to strengthen the surface potential of electret melt-blown fabrics. Figure 3 shows that the fabrics have comparable surface potentials when the electric field intensities are 1.5 and $2.0 \mathrm{kV} / \mathrm{cm}$ because the electric field intensity fails to provide enough energy in one minute. When the electric field intensity is $2.5 \mathrm{kV} / \mathrm{cm}$, there is a significant rise in the surface voltage (Figure 3c). Increasing the ratio of $\mathrm{TiO}_{2}$ improves the surface voltage, especially for the case of $3 \mathrm{wt} \%$ of $\mathrm{TiO}_{2}$, which helps to reach the maximal surface voltage. Nonetheless, $4 \mathrm{wt} \%$ of $\mathrm{TiO}_{2}$ adversely affects the surface voltage due to the agglomeration of $\mathrm{TiO}_{2}$.

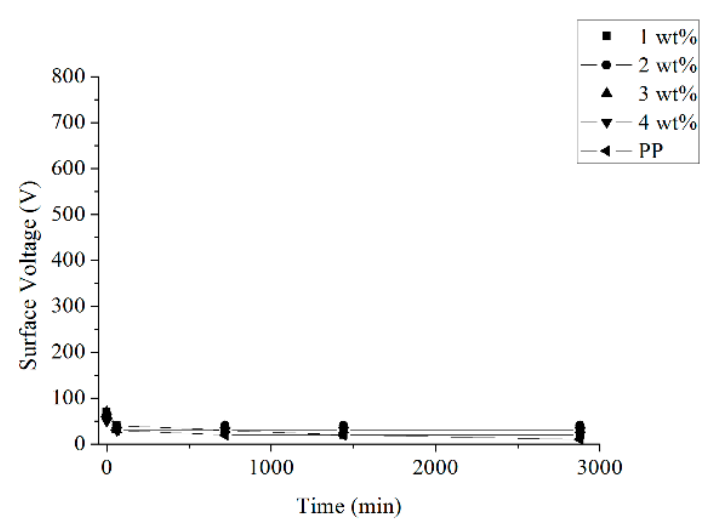

(a)

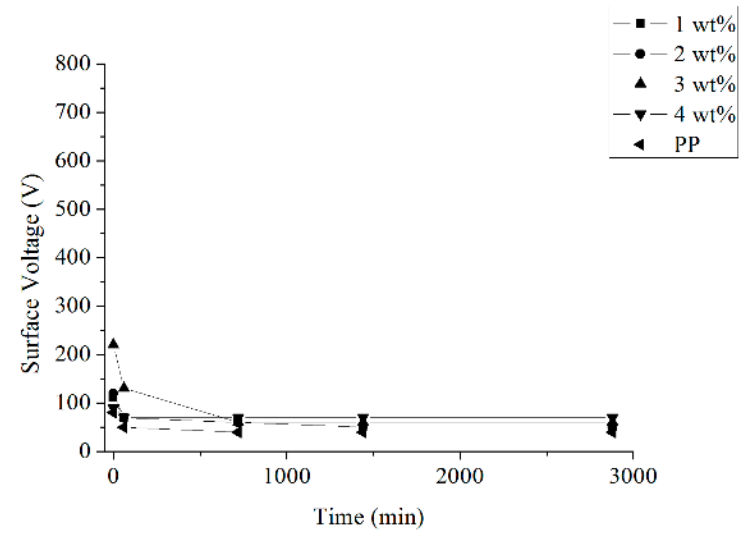

(b)

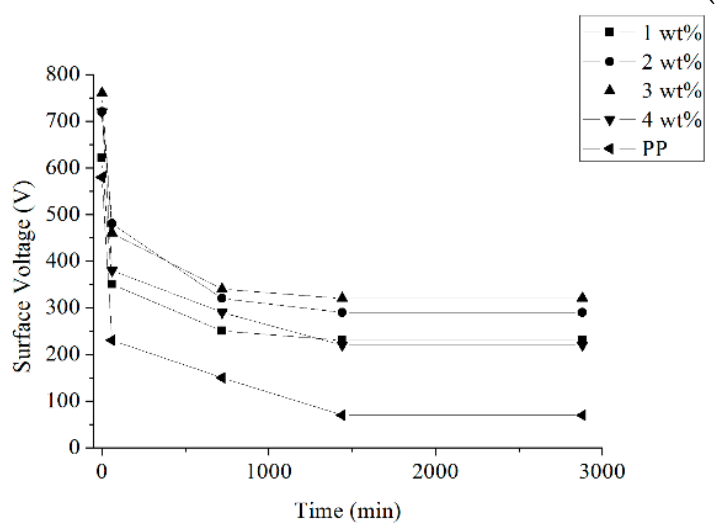

(c)

Figure 3. Surface voltage of electret melt-blown fabrics as related to the ratio of $\mathrm{TiO}_{2}(1,2,3$, and $4 \mathrm{wt} \%$ ) and electric field intensities of (a) $1.5,(\mathbf{b}) 2.0$, and (c) $2.5 \mathrm{kV} / \mathrm{cm}$.

Table 2 indicates that the crystallinity increases when $\mathrm{TiO}_{2}$ increases from 1 to $3 \mathrm{wt} \%$, but the crystallinity descends with $4 \mathrm{wt} \%$ of $\mathrm{TiO}_{2}$ and is similar to that with $2 \mathrm{wt} \%$ of $\mathrm{TiO}_{2}$. The descending crystallinity may be ascribed to the agglomeration of $\mathrm{TiO}_{2}$. Moreover, surface voltage is also dependent on the crystallinity. The interface between crystallization and amorphous regions becomes a trap against charge storage $[14,28,29]$. A lower crystallinity diminishes the region available to store charges, which in turn reduces the surface voltage. In Figure 3c, the melt-blown fabrics made of 1 and $4 \mathrm{wt} \%$ of $\mathrm{TiO}_{2}$ exhibit comparable surface voltages in terms of the trend and the value. The electret electric charges of $\mathrm{TiO}_{2}$ are mainly stored over its particles [20], so $4 \mathrm{wt} \%$ of $\mathrm{TiO}_{2}$ does not acquire the surface area as expected, which is attributed to the agglomeration. Moreover, the space charges from crystalline and amorphous regions are also decreased. Both factors render the melt-blown fabrics made of 1 and 
$4 \mathrm{wt} \%$ of $\mathrm{TiO}_{2}$ with similar surface voltages. The variation in the crystallinity changes the apparent enthalpy of crystallization, which subsequently shifts the temperature of Tc and Tm. The stability of electrostatic charges in melt-blown fabrics is pertinent to the surface potential, which can be computed with the following equation:

$$
\text { Surface Potential }=\frac{V}{V_{0}}
$$

where $V$ is the surface voltage that changes with time, and $V_{0}$ is the initial surface voltage.

Table 2. Thermal properties of samples as related to the ratio of $\mathrm{TiO}_{2}$ being $1,2,3$, and $4 \mathrm{wt} \%$.

\begin{tabular}{cccc}
\hline $\mathrm{TiO}_{\mathbf{2}}$ Ratio $(\mathbf{w t} \mathbf{\%})$ & $\mathbf{T}_{\mathbf{c}}\left({ }^{\circ} \mathbf{C}\right)$ & $\mathbf{T}_{\mathbf{m}}\left({ }^{\circ} \mathbf{C}\right)$ & Crystallinity $(\mathbf{\%})$ \\
\hline Pure PP & 121.0 & 146.6 & 6.9 \\
1 & 120.0 & 159.6 & 15.3 \\
2 & 122.2 & 149.9 & 15.1 \\
3 & 118.3 & 147.7 & 22.3 \\
4 & 118.2 & 144.5 & 16.2 \\
\hline
\end{tabular}

Based on Figure 4a-c, the initial surface voltage appears relatively lower at 1.5 and $2.0 \mathrm{kV} / \mathrm{cm}$, which in turn makes the surface potential higher than the surface potential of $2.5 \mathrm{kV} / \mathrm{cm}$. In particular, $3 \mathrm{wt} \%$ of $\mathrm{TiO}_{2}$ provides the fabrics with an optimal surface potential, which corresponds to the surface voltage. $\mathrm{TiO}_{2}$ is a material with a high dielectric constant and a low conductivity, and thus can effectively strengthen the charge storage and stability [19]. At the same time, it also serves as an initial point for heterogeneous nucleation, which facilitates the crystallinity of polymer and effectively enlarges the contact area between crystalline and amorphous regions, which is a trap for charge storage. Hence, the surface potential can be significantly improved [14,15,17].

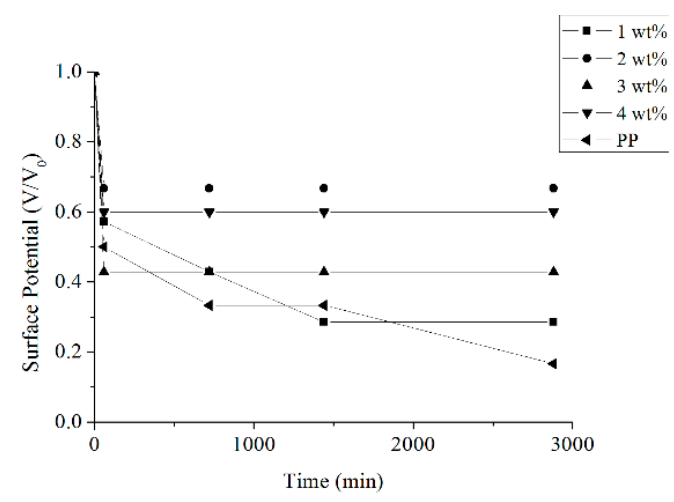

(a)

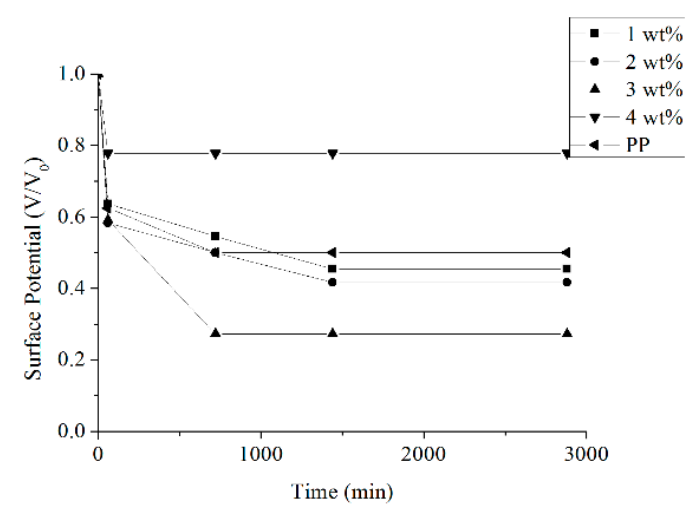

(b)

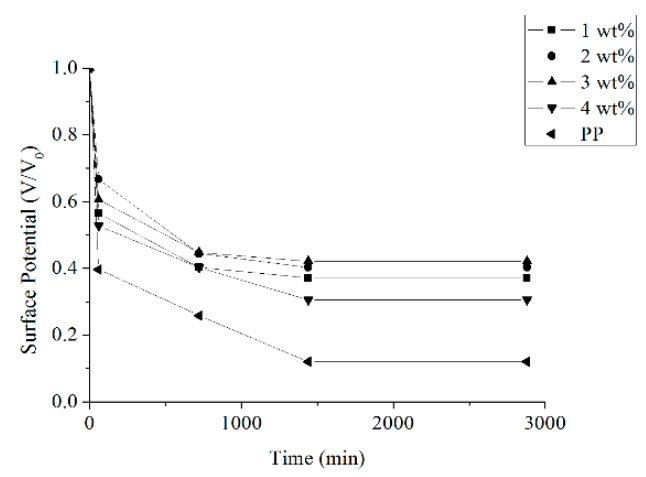

(c)

Figure 4. Surface potential of electret melt-blown fabrics as related to the ratio of $\mathrm{TiO}_{2}(1,2,3$, and $4 \mathrm{wt} \%$ ) and electric field intensities of (a) 1.5 , (b) 2.0 , and (c) $2.5 \mathrm{kV} / \mathrm{cm}$. 


\subsection{Surface Resistivity}

In light of the study by Viraneva et al., the electrostatic charge of electret exhibits stability that is dependent on the charge storage of particles, space charge of polymers, and the conductivity, the latter of which may also affect the storage of electric charges [21]. The relationship between the $\mathrm{TiO}_{2}$ ratio and the surface resistivity is shown in Table 3. An increase in $\mathrm{TiO}_{2}$ adversely affects the surface resistivity of melt-blown fabrics. Namely, a lower surface resistivity means equivalently a greater electrical conductivity, which dissipates electric charges efficiently. Subsequently, with $4 \mathrm{wt} \% \mathrm{of} \mathrm{TiO}_{2}$, the surface resistivity of melt-blown fabrics descends in a short time and eventually resembles that of melt-blown fabrics consisting of $1 \mathrm{wt} \%$ of $\mathrm{TiO}_{2}$ as per Figure 3c. In addition, Zha et al. found that significant variations were not presented until $\mathrm{TiO}_{2}$ exceeded $5 \mathrm{wt} \%$ [22]. By contrast, in this study, $1 \mathrm{wt} \%$ of $\mathrm{TiO}_{2}$ instantly causes a difference, which is ascribed to the difference in the membrane and fiber structures. The electric charges of membranes are freely transmitted along any direction, whereas the electric charges of a fibrous structure are only allowed to be transmitted along the fiber direction (i.e., the direction that is perpendicular to the fiber diameter). Subsequently, melt-blown fabrics exhibit a difference in the surface resistivity when the $\mathrm{TiO}_{2}$ ratio is low.

Table 3. Surface resistivity of melt-blown fabrics as related to the $\mathrm{TiO}_{2}$ ratio.

\begin{tabular}{cc}
\hline $\mathrm{TiO}_{\mathbf{2}}$ Ratio (wt\%) & Surface Resistivity $(\Omega / \mathrm{SQ})$ \\
\hline Pure PP & $2.71 \times 10^{11} \pm 4.96 \times 10^{10}$ \\
\hline 1 & $1.79 \times 10^{11} \pm 7.12 \times 10^{9}$ \\
\hline 2 & $1.63 \times 10^{11} \pm 5.62 \times 10^{9}$ \\
\hline 3 & $1.43 \times 10^{11} \pm 1.50 \times 10^{10}$ \\
\hline 4 & $9.15 \times 10^{10} \pm 1.24 \times 10^{10}$ \\
\hline
\end{tabular}

\subsection{Filtration Efficiency}

After being in storage for two days, the surface voltage of electret melt-blown fabrics was stabilized, and then the samples were tested for filtration efficiency. In Figure 5 it can be seen that either a rise in $\mathrm{TiO}_{2}$ or electric field intensity has a positive influence on the filtration efficiency. The filtration efficiency and surface voltage demonstrate the same trend, which suggests that the presence of $\mathrm{TiO}_{2}$ can heighten the filtration efficiency. Specifically, an electric field intensity of $2.5 \mathrm{kV} / \mathrm{cm}$, rather than 1.5 or $2.0 \mathrm{kV} / \mathrm{cm}$, helps to retain a relatively higher surface voltage, which contributes to higher filtration efficiency. In addition to mechanical filtration, electret also adsorbs particles with the help of electrostatic forces. Figure 6 shows that non-electret pure PP melt-blown fabrics do not perform well when filtering particles at sizes of $0.4-2.5 \mu \mathrm{m}$. The mechanical filtration is realized by means of inertial impaction, interception, Brownian diffusion, and gravitational settling. As for particles at sizes exceeding $2.5 \mu \mathrm{m}$, they can be effectively filtered simply by mechanical filtration. However, for particles that are smaller than $2.5 \mu \mathrm{m}$, especially smaller than $100 \mathrm{~nm}$, the employment of mechanical filtration is not satisfactory [30]. Using static electricity to adsorb particles smaller than $2.5 \mu \mathrm{m}$ has been proven effective. Particles are polarized as a result of the electric fields caused by the charged fibers in the proximity. The polarized particles are then adsorbed by the charged fibers, thereby acquiring the filtration efficiency of the static electricity adsorption. The higher the surface voltage, the better the particle adsorption performance. With an electric field intensity of $2.5 \mathrm{kV} / \mathrm{cm}$, the melt-blown fibers exhibit good filtration efficiency of particles of $0.03-2.5 \mu \mathrm{m}$ regardless of the $\mathrm{TiO}_{2}$ ratio (Figure 6). In particular, the melt-blown fibers composed of $3 \mathrm{wt} \%$ of $\mathrm{TiO}_{2}$ have filtration efficiency higher than $92 \%$ when the particle size is between 0.03 and $2.5 \mu \mathrm{m}$. 


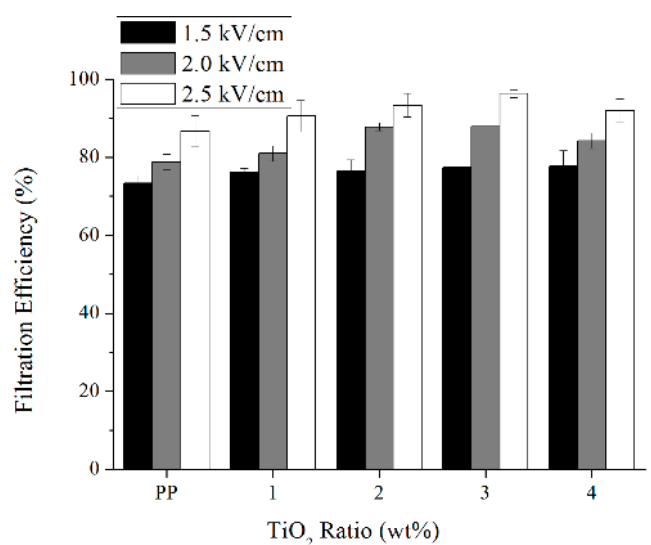

Figure 5. Filtration efficiency of electret melt-blown fabrics as related to the ratio of $\mathrm{TiO}_{2}(1,2,3$, and $4 \mathrm{wt} \%$ ) and electric field intensities of (a) 1.5 , (b) 2.0 , and (c) $2.5 \mathrm{kV} / \mathrm{cm}$. The filtration efficiency of non-electret pure polypropylene (PP) melt-blown fabrics is $72.67 \% \pm 1.42 \%$.

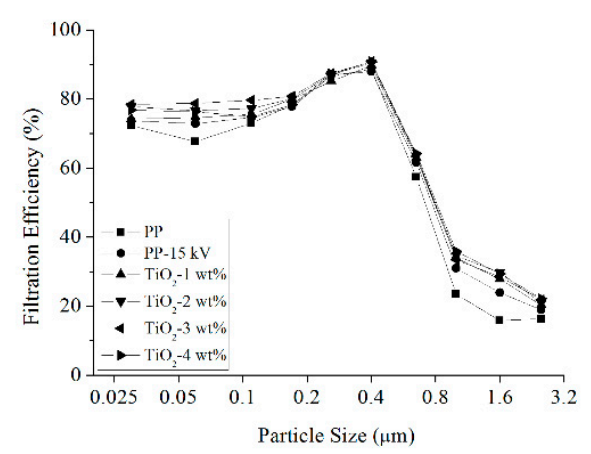

(a)

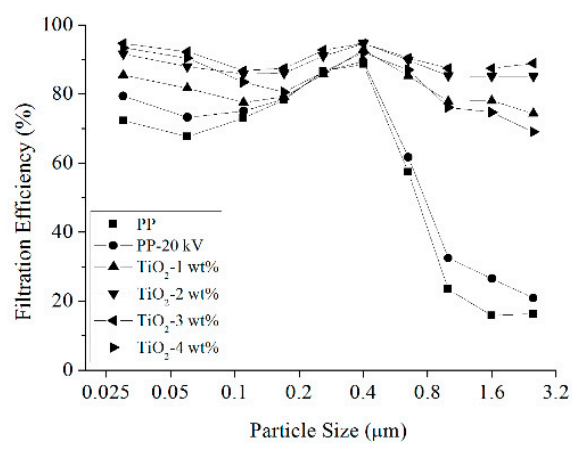

(b)

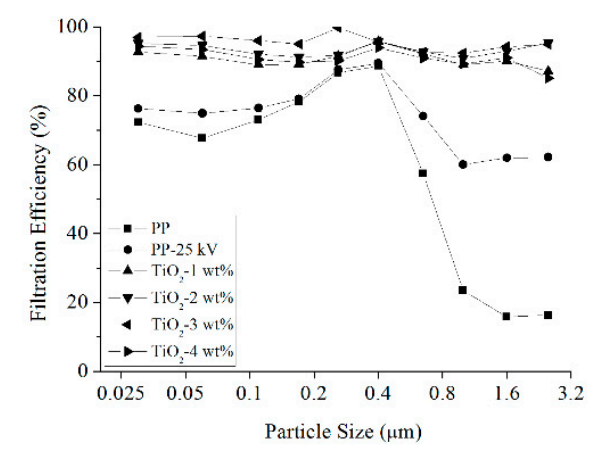

(c)

Figure 6. Filtration efficiency of particles at various sizes for electret melt-blown fabrics as related to ratios of 1, 2, 3, and $4 \mathrm{wt} \%$ and the electric field intensities of (a) 1.5, (b) 2.0 , and (c) $2.5 \mathrm{kV} / \mathrm{cm}$.

Another important evaluation of filtration measurement is pressure drop performance. Figure 7 shows that the significant pressure drop is absent in all samples because they have to remain as a consistent structure. As a result, the influence of surface voltage on filtration efficiency can be measured accurately. Hence, the basis weight, thickness, fiber diameter, and air permeability of samples are identical in Table 1. Quality factor is commonly used to compare the filtration efficiency between different filters, and the equation is as follows:

$$
Q_{f}=\frac{-\ln (1-E)}{\Delta P}
$$


where $Q_{f}$ is the quality factor, $E$ is the filter efficacy, and $\Delta P$ is the reduction voltage [31].

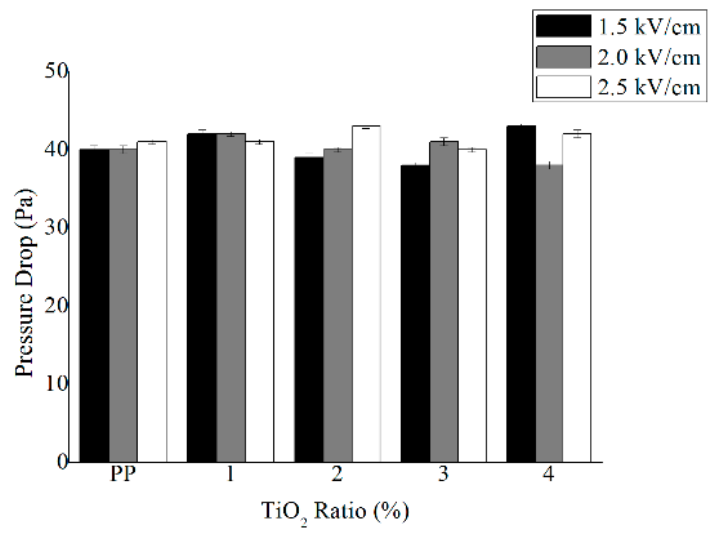

Figure 7. Pressure drop of electret melt-blown fabrics as related to the ratio of $\mathrm{TiO}_{2}(1,2,3$, and $4 \mathrm{wt} \%)$ and electric field intensities of (a) 1.5, (b) 2.0, and (c) $2.5 \mathrm{kV} / \mathrm{cm}$. The pressure drop of non-electret pure PP melt-blown fabrics is $40 \pm 0.5 \mathrm{~Pa}$.

The quality factor is improved with a greater ratio of $\mathrm{TiO}_{2}$ or higher electric field intensity (Figure 8). The pressure drop pertains to the structure of samples, and the parameters do not alter the structure. Zhang et al. found that the quality factor of commercially available melt-blown fabrics was $0.033 \mathrm{~Pa}^{-1}$ [31]. In comparison, the proposed electret melt-blown fabrics outperform the commercially available ones in terms of filtration efficiency. In particular, the quality factor reaches $0.083 \mathrm{~Pa}^{-1}$ when $\mathrm{TiO}_{2}$ is $3 \mathrm{wt} \%$ and the electric field intensity is $2.5 \mathrm{kV} / \mathrm{cm}$.

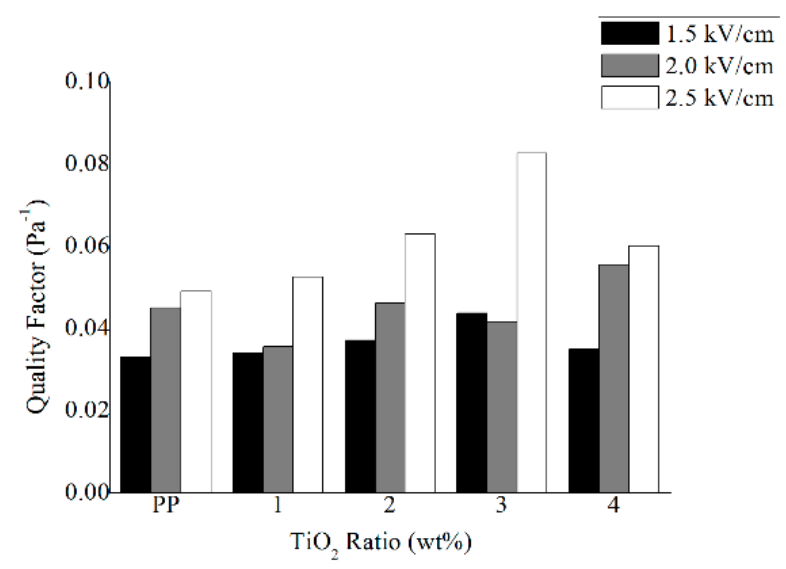

Figure 8. Quality factor of electret melt-blown fabrics as related to the ratio of $\mathrm{TiO}_{2}(1,2,3$, and $4 \mathrm{wt} \%)$ and electric field intensities of (a) 1.5 , (b) 2.0 , and (c) $2.5 \mathrm{kV} / \mathrm{cm}$. The quality factor of non-electret pure PP melt-blown fabrics is 0.032 .

\section{Conclusions}

This study proposes using a low-cost and high-dielectric-constant mineral of $\mathrm{TiO}_{2}$ to improve the filtration efficiency of electret melt-blown fabrics. The results indicate that a greater ratio of $\mathrm{TiO}_{2}$ has a positive influence on the surface voltage and filtration efficiency of the filters. In addition, $\mathrm{TiO}_{2}$ also facilitates the rate of crystallinity of polymer to strengthen the filtration efficiency. Finally, the quality factor of the proposed $\mathrm{TiO}_{2}$-reinforced electret melt-blown fabrics is $0.083 \mathrm{~Pa}^{-1}$, which is significantly higher than that $\left(0.033 \mathrm{~Pa}^{-1}\right)$ of the commercially available melt-blown fabrics, thus making these fabrics qualified candidates for masks and other staple filter fields. 
Author Contributions: Conceptualization, J.-H.L.; Data Curation, Y.-H.S; Investigation, Y.-H.S; Supervision, J.-H.L., C.-H.H., Y.-S.C., S.-A.L., and C.-W.L.; Writing-Original Draft Preparation, Y.-H.S.; Writing-Review and Editing, J.-H.L. and C.-W.L. All authors have read and agreed to the published version of the manuscript.

Funding: This research received no external funding.

Acknowledgments: This research project is financially supported by the Ministry of Science and Technology of Taiwan under the Contract MOST 107-2622-E-035-011-CC3, MOST 107-2221-E-468-021, and MOST 107-2622-E-468-C3. Jia-Horng Lin and Yueh-Sheng Chen contributed equally to this work.

Conflicts of Interest: The authors declare that they have no conflict of interest in the collection, analyses, or interpretation of data; in the writing of the manuscript; and in the decision to publish the results.

\section{References}

1. Weber, S.A.; Insaf, T.Z.; Hall, E.S.; Talbot, T.O.; Huff, A.K. Assessing the impact of fine particulate matter (PM2.5) on respiratory cardiovascular chronic diseases in the New York City Metropolitan area using Hierarchical Bayesian Model estimates. Environ. Res. 2016, 151, 399-409. [CrossRef] [PubMed]

2. Zhang, J.F.; Chen, G.J.; Bhat, G.S.; Azari, H.; Pen, H.L. Electret characteristics of melt-blown polylactic acid fabrics for air filtration application. J. Appl. Polym. Sci. 2019, 137, 6. [CrossRef]

3. Han, K.S.; Lee, S.; Kim, M.; Park, P.; Lee, M.H.; Nah, J. Electrically Activated Ultrathin PVDF-TrFE Air Filter for High-Efficiency PM1.0 Filtration. Adv. Funct. Mater. 2019, 29, 7. [CrossRef]

4. Kim, M.W.; An, S.; Seok, H.; Yoon, S.S.; Yarin, A.L. Electrostatic Transparent Air Filter Membranes Composed of Metallized Microfibers for Particulate Removal. ACS Appl. Mater. Interfaces 2019, 11, 26323-26332. [CrossRef] [PubMed]

5. Sun, Q.Q.; Leung, W.W.F. Charged PVDF multi-layer filters with enhanced filtration performance for filtering nano-aerosols. Sep. Purif. Technol. 2019, 212, 854-876. [CrossRef]

6. Chang, D.Q.; Liu, J.X.; Chen, S.C. Factors Affecting Particle Depositions on Electret Filters Used in Residential HVAC Systems and Indoor Air Cleaners. Aerosol Air Qual. Res. 2018, 18, 3211-3219. [CrossRef]

7. Kilic, A.; Shim, E.; Yeom, B.Y.; Pourdeyhimi, B. Improving electret properties of PP filaments with barium titanate. J. Electrost. 2013, 71, 41-47. [CrossRef]

8. Yuan, Y.L.; Zhao, J.; Dong, C.L.; Shao, Y.Q.; Liu, Y.Y.; Li, J.Z.; Zhong, C.; Ye, L.; Song, R.; Zhang, H.; et al. Improved Electret Properties of Poly(Vinylidene Fluoride)/Lithium Niobate Nanocomposites for Applications in Air Filters. Macromol. Mater. Eng. 2019, 304, 10. [CrossRef]

9. Gobi, N.; Vijayalakshmi, E.; Robert, B.; Srinivasan, N.R. Development of PAN nano fibrous filter hybridized by $\mathrm{SiO}_{2}$ nanoparticles electret for high efficiency air filtration. J. Polym. Mater. 2018, 35, 317-328. [CrossRef]

10. Huang, Z.X.; Liu, X.X.; Zhang, X.; Wong, S.C.; Chase, G.G.; Qu, J.P.; Baji, A. Electrospun polyvinylidene fluoride containing nanoscale graphite platelets as electret membrane and its application in air filtration under extreme environment. Polymer 2017, 131, 143-150. [CrossRef]

11. Kilic, A.; Shim, E.; Pourdeyhimi, B. Electrostatic Capture Efficiency Enhancement of Polypropylene Electret Filters with Barium Titanate. Aerosol Sci. Technol. 2015, 49, 666-673. [CrossRef]

12. Wang, N.; Cai, M.; Yang, X.; Yang, Y.Y. Electret nanofibrous membrane with enhanced filtration performance and wearing comfortability for face mask. J. Colloid Interface Sci. 2018, 530, 695-703. [CrossRef] [PubMed]

13. Zhang, H.F.; Liu, J.X.; Zhang, X.; Huang, C.; Jin, X.Y. Design of electret polypropylene melt blown air filtration material containing nucleating agent for effective PM2.5 capture. RSC Adv. 2018, 8, 7932-7941. [CrossRef]

14. Xiao, H.M.; Gui, J.Y.; Chen, G.J.; Xiao, C.P. Study on correlation of filtration performance and charge behavior and crystalline structure for melt-blown polypropylene electret fabrics. J. Appl. Polym. Sci. 2015, 132, 6. [CrossRef]

15. Li, T.T.; Cen, X.X.; Ren, H.T.; Sun, F.; Lin, Q.; Lou, C.W.; Lin, J.H. One-Step Bark-Like Imitated Polypropylene (PP)/Polycarbonate (PC) Nanofibrous Meltblown Membrane for Efficient Particulate Matter Removal. Polymers 2019, 11, 18. [CrossRef]

16. Yu, B.; Han, J.; Sun, H.; Zhu, F.C.; Zhang, Q.; Kong, J.J. The Preparation and Property of Poly(lacticacid)/ Tourmaline Blends and Melt-Blown Nonwoven. Polym. Compos. 2015, 36, 264-271. [CrossRef]

17. Kilic, A.; Shim, E.; Pourdeyhimi, B.; Yeom, B.Y. Aerosol Filtration Properties of Nucleating Agent Containing Electret Filters. Polym. Eng. Sci. 2014, 54, 1533-1539. [CrossRef] 
18. Dreno, B.; Alexis, A.; Chuberre, B.; Marinovich, M. Safety of titanium dioxide nanoparticles in cosmetics. J. Eur. Acad. Dermatol. Venereol. 2019, 33, 34-46. [CrossRef]

19. Tyagi, A.; Singh, N.; Sharma, Y.; Gupta, R.K. Improved supercapacitive performance in electrospun $\mathrm{TiO}_{2}$ nanofibers through Ta-doping for electrochemical capacitor applications. Catal. Today 2019, 325, 33-40. [CrossRef]

20. Prateek; Bhunia, R.; Siddiqui, S.; Garg, A.; Gupta, R.K. Significantly Enhanced Energy Density by Tailoring the Interface in Hierarchically Structured $\mathrm{TiO}_{2}-\mathrm{BaTiO} 3-\mathrm{TiO}_{2}$ Nanofillers in PVDF-Based Thin-Film Polymer Nanocomposites. ACS Appl. Mater. Interfaces 2019, 11, 14329-14339. [CrossRef]

21. Viraneva, A.; Yovcheva, T.; Bodurov, I.; Galikhanov, M. Effect of $\mathrm{TiO}_{2}$ particle incorporation on the electret properties of corona charged polypropylene composite films. Bulg. Chem. Commun. 2013, 45, 73-76.

22. Zha, J.W.; Dang, Z.M.; Song, H.T.; Yin, Y.; Chen, G. Dielectric properties and effect of electrical aging on space charge accumulation in polyimide/ $\mathrm{TiO}_{2}$ nanocomposite films. J. Appl. Phys. 2010, 108, 6. [CrossRef]

23. Chawengkijwanich, C.; Pokhum, C.; Srisitthiratkul, C.; Subjalearndee, N.; Pongsorrarith, V.; Yaipimai, W.; Phanomkate, N.; Intasanta, V. Fabrication of Water-Based $\mathrm{TiO}_{2}$-Coated Pleated Synthetic Fiber toward Photocatalytic Oxidation of VOCs and CO for Indoor Air Quality Improvement. J. Environ. Eng. ASCE 2019, 145, 9. [CrossRef]

24. Wongwatcharapaiboon, J.; Gan, G.H.; Riffat, S.B. A new air PM2.5 filtrative lamp with a combination of fabric filter and $\mathrm{TiO}_{2}$ coating mop. Int. J. Low Carbon Technol. 2019, 14, 394-399. [CrossRef]

25. Xu, C.W.; Xie, W.X.; Yu, Y.; Zhang, J.; Yang, J.G. Photocatalytic and Filtration performance study of $\mathrm{TiO}_{2} / \mathrm{CNTs}-$ Filter for oil particle. Process. Saf. Environ. Protect. 2019, 123, 72-78. [CrossRef]

26. Ho, C.C.; Kang, F.; Chang, G.M.; You, S.J.; Wang, Y.F. Application of recycled lanthanum-doped $\mathrm{TiO}_{2}$ immobilized on commercial air filter for visible-light photocatalytic degradation of acetone and NO. Appl. Surf. Sci. 2019, 465, 31-40. [CrossRef]

27. Li, Y.H.; Cheng, S.W.; Yuan, C.S.; Lai, T.F.; Hung, C.H. Removing volatile organic compounds in cooking fume by nano-sized $\mathrm{TiO}_{2}$ photocatalytic reaction combined with ozone oxidation technique. Chemosphere 2018, 208, 808-817. [CrossRef]

28. Cao, G.X.; Zhang, X.Q.; Zhao, D.; Zhang, C.; Wang, B.; Zeng, C.C. Charge Storage and Transport in Oriented and Non-oriented Polytetrafluoroethylene Films. IEEE Trans. Dielectr. Electr. Insul. 2012, 19, 1108-1115. [CrossRef]

29. Xia, Z.F.; Gerhard-Multhaupt, R.; Kunstler, W.; Wedel, A.; Danz, R. High surface-charge stability of porous polytetrafluoroethylene electret films at room and elevated temperatures. J. Phys. D Appl. Phys. 1999, 32, L83-L85. [CrossRef]

30. Wang, C.S.; Otani, Y. Removal of Nanoparticles from Gas Streams by Fibrous Filters: A Review. Ind. Eng. Chem. Res. 2013, 52, 5-17. [CrossRef]

31. Zhang, H.; Zhen, Q.; Liu, Y.; Liu, R.T.; Zhang, Y.F. One-step melt blowing process for PP/PEG micro-nanofiber filters with branch networks. Results Phys. 2019, 12, 1421-1428. [CrossRef]

(C) 2020 by the authors. Licensee MDPI, Basel, Switzerland. This article is an open access article distributed under the terms and conditions of the Creative Commons Attribution (CC BY) license (http://creativecommons.org/licenses/by/4.0/). 